\title{
RESPONSABILIDADE FILIAL NO CUIDADO AOS PAIS IDOSOS E A SOBRECARGA DOS CUIDADORES
}

Laísa Cargnin; Universidade Regional Integrada do Alto Uruguai e das Missões, Campus Frederico

Westphalen; E-mail: pc.marcelalaisa@gmail.com;

Marília Bruna Murari; Universidade Regional Integrada do Alto Uruguai e das Missões, Campus Frederico

Westphalen; E-mail: mariliabmurari@hotmail.com;

Laura Franco Sponchiado; Universidade Regional Integrada do Alto Uruguai e das Missões, Campus Frederico Westphalen; E-mail: laura_sponchiado011@hotmail.com;

Marines Aires; Universidade Regional Integrada do Alto Uruguai e das Missões, Campus Frederico Westphalen; E-mail: maires@uri.edu.br;

\section{RESUMO}

Introdução: A responsabilidade filial é uma norma social relacionada ao comportamento dos filhos no cuidado aos pais idosos que pode influenciar na saúde do cuidador levando ao aumento da sobrecarga. Objetivo: Analisar a responsabilidade filial no cuidado aos pais idosos e a repercussão deste cuidado no bem-estar dos filhos. Métodos: Estudo misto com amostra de 100 filhos cuidadores de idosos da Região Noroeste do Rio Grande do Sul. Para a coleta de dados é utilizado o protocolo de Responsabilidade filial adaptado e validado para uso no Brasil, composto por questões abertas e fechadas e sete escalas. O projeto foi aprovado pelo Comitê de Ética ( $n^{\circ}$ 1.997.406). Resultados: A amostra foi composta por 86 filhos sendo que $(61,6 \%)$ são filhas com média de idade $45,41 \pm 10,767$ anos, a média dos anos de estudo foi de 10,83 $\pm 5,296$ ano e $58,1 \%$ possuía emprego formal. A sobrecarga do cuidador foi maior no domínio tempo dependente $(9,32 \pm 6,592)$. As atitudes de responsabilidade filial avaliadas pelas Escalas de Expectativa Filial e Dever Filial apresentaram respectivamente uma média de $22,8 \pm 3,8$ e 29,2 $\pm 2,4$. A etapa qualitativa elaborou-se quatro categorias: possibilidade de institucionalização dos pais idosos, expectativa de cuidado, dificuldades em ser filho cuidador e sentimentos de responsabilidade filial. Conclusão: Os resultados demonstram, que os filhos sentem responsáveis pelo cuidado aos pais, porém cuidar do idoso em tempo integral pode acarretar prejuízos na saúde do cuidador levando a uma maior sobrecarga.

Palavras-chave: Saúde do Idoso; Cuidadores; Enfermagem Geriátrica. 